\title{
PACE UNIVERSITY, BLENDED LEARNING AND LOCALNESS: A MODEL THAT WORKS
}

\author{
David Sachs
}

Pace University

\begin{abstract}
Several forms of blended learning at Pace University offer flexible options for learners, and its growth reflects its appeal to traditional and corporate learners.
\end{abstract}

\section{KEYWORDS}

Blended Learning, Mission, Computing, Communications, Flexibility

\section{BACKGROUND}

Since 1996, Pace University, primarily through the Seidenberg School of Computer Science and Information Systems, has been actively involved in online education in the style known as asynchronous learning networks (ALN). Perhaps best known is the NACTEL program; an online array of undergraduate and graduate degrees provided $100 \%$ online to individuals in the telecommunications industry. This program, in place since 1999, has offered high quality online education to several thousand individuals throughout the United States, who work in five different time zones under some challenging conditions. For more information about the NACTEL program, see http://csis.pace.edu/nactel.

More recently, the School and the University have been focusing on blended or hybrid learning. For purposes of this discussion, let's take a moment to define what we mean by blended learning. Pace University has defined blended learning in several ways. The first way, and the one that the University has labeled "Web assisted" is when a significant percentage (one third or more) of face-to-face time in a given course is "replaced by" online time that enables individuals to come to the University less often than would have been previously required. A good example of a blended course or "Web assisted" course is CIS101 in which some 1,000 students per semester now meet for two "face-to-face" hours each week, and "one hour" of the course is taught online.

A second way that the term blended has come to be used is when a given set of courses (a certificate or degree) consists of some courses that are taught $100 \%$ in a classroom and others that are taught $100 \%$ online in ALN format. The MS in Software Design and Engineering is a good example of a blended degree. Some of the courses in the degree are held "face-to-face," since they require significant face-toface group and team work. Other courses within the degree are taught $100 \%$ online in ALN format. Overall, the degree is perceived by both students and faculty members to be a blended degree.

Another example of a blended degree is the Doctor of Professional Studies in Computing degree. In this instance, each and every course within the degree is blended, and the degree as a whole is perceived to be blended. Individuals must be on campus 6 times each semester, for a Friday evening and Saturday full day set of classes. All of their other instruction and student work is done, in traditional ALN format, $100 \%$ online. Individuals pursuing the Doctor of Professional Studies in Computing degree come to the 
University from as far away as California and as nearby as White Plains. In all instances, the fact that the degree is blended is what has made it work.

All three formats of blended teaching and learning are currently supported by the Seidenberg School and the University and all of them have added significantly to the mission of the School and the University. Let's look at three examples.

\section{A. Example \#1: CIS101}

Several years ago, it became clear that the CIS101 course-an introductory course taught by Seidenberg faculty members to over 1,000 undergraduates each semester-had some challenges. One challenge had to do with the size of the lectures - 72 students — and the other had to do with the overall design of the course. It became clear that blended learning would provide the perfect solution. Blended learning would provide better teaching environments. Students would come together for one two-hour course meeting each week-with no more than 28 students in the class. The other hour of instruction would be provided online. All of the students are local—and many of them need or want more flexibility in their schedules. Such flexibility provides students with other course opportunities, and perhaps with some work options as well.

CIS101 has been described as follows: "This course introduces students to the essential knowledge required to achieve a well-rounded understanding of the explosive impact of the Internet and technology in all aspects of modern society. Computers are now the primary means of information retrieval, analysis and communication among individuals and organizations throughout the world. CIS101 provides students with the understanding of computer terminology, hardware, and software necessary to explore the resources of the Internet and exploit technology to its fullest on both a personal and professional level." Prior to redesigning this course, and using a blended approach to teaching it, significant questions were being raised about whether any or all of these goals were being met.

The redesign team consciously chose to reconstruct CIS101 in such a way that for part of it (two course hours each week) students would continue to meet face-to-face, in groups of 28, with their professor. The other face-to-face hour each week would be replaced by online course instruction. This would serve several purposes. Students would learn about online instruction, they could access their course materials for this one hour of instruction "anytime, anywhere" and they could have more flexibility in their lives. The course redesign team focused heavily on determining which course materials worked best and where. Students in CIS101 are surveyed several times each semester. It is abundantly clear that the new course design for CIS101 works well. Students have much greater access to their professors, they have more flexibility in their schedules, and they are becoming gently and caringly introduced to online education.

\section{B. Example \#2: The Doctorate in Professional Computing Degree}

Without a blended/local approach to education, Pace University's Doctorate in Professional Computing degree would most likely not be possible. Since 1999, this degree has attracted individuals who for the most part live nearby - within about 50 miles from the University campus - (as well as some who live farther away) who wish to participate in an educational offering that is demanding, time consuming and flexible. Students must be on campus 5 or 6 weekends (Friday night and all day Saturday) each semester. All of their other work is conducted online. This degree, intended for full-time working IT and education professionals, offers the "best of both worlds" to these adults. They have the opportunity to interact faceto-face with their classmates, and they also have the chance to maintain their full-time jobs and family and community obligations. 
Blended learning has been the key to the success of the Doctorate in Professional Computing degree. When students are surveyed about the mix of on-campus face-to-face time and the off-campus online time, they always tell us that the mix is a perfect one. They value the on-campus time that can be used for group work, hands-on labs, and face-to-face meetings with their advisors and professors. And, for many of them, the conversation continues during those in-between times. They work in teams, and they provide each other with research and reports and conversations, all online, when they are not on campus. Students use a wide array of technology, in truly blended format, during the three or four years that they participate in this degree. They communicate regularly and effectively with each other, and quickly and easily go back and forth between the on-ground face-to-face meetings and the online email, attached files and Instant Messenger meetings that occur in between.

\section{Example \#3: The Bank of New York Project}

The Bank of New York Project began in January 2006. Approximately 40 individuals from the Bank of New York are actively involved in pursuing two graduate certificates-one in Software Design and Development and one in Secure Software Development. All of the instruction is provided on-site by Pace University professors at a nearby Bank of New York location. It is clear that face-to-face instruction is important to the Bank and to the students. Students value the time that they spend with their professors and eagerly look forward to working closely with them in a classroom setting.

It is also clear that blended learning has made a huge difference with this particular project, primarily with respect to calendar flexibility. Banks regularly close for certain holidays (Martin Luther King Day, Presidents Day, etc.) and, in this case, that would have meant that the classes either would not have met those given weeks, or would have had to find other time to meet. Instead, it was "blended learning to the rescue". Both cohorts of students were provided with Blackboard course shells for their classes, and professors were able to successfully integrate their online teaching with their on-ground instruction. When professors knew in advance that their classes were not going to meet, they were able to put all of the necessary course materials into the Blackboard shell, and the courses met anyway. And, when an unexpected snowstorm occurred and wiped out another scheduled class meeting, the class was again able to continue quite effectively.

Blended learning also provided a helpful answer to a calendar challenge. The Bank and the University wished to offer students a late Spring term — but it was also clear that the calendar would permit only offering a nine-week term ending by July $1^{\text {st }}$, rather than the usual 12 -week one. Once again, blended learning provided the answer. Classes met face-to-face for nine class meetings, but students also had a significant amount of additional work (the equivalent of three weeks' worth) provided to them in an online fashion.

And finally, when it became clear that there was a need for students to have a Java class in their lives and that it would have to be scheduled during the summer, it was blended learning that made that possible. Students were enrolled in a nine-week face-to-face class as well as a nine-week online class. They were permitted to attend either or both of the classes, and some students moved back and forth easily from one to the other. The professor who was teaching the students (and who was teaching both sections) knew them all, and "met them all" each week, one place or the other. Blended learning worked well in this case; the course took place during July and August while students came and went and they never had to miss a class.

\section{IMPLICATIONS FOR THE FUTURE}

Blended learning is providing Pace University and the Seidenberg School of Computer Science and 
Information Systems with a wonderful variety of teaching options to offer to both the regular traditional undergraduate and graduate students as well as to corporate clients. Traditional students are "voting with their feet" to have blended learning experiences in their lives. Sometimes they are taking courses that are listed in our University online catalog as "Web assisted" (the term that the University chose to use for hybrid or blended courses). For the most recent year (2005-2006), approximately 15\% of the University's 14,000 students took at least one course that was a "Web assisted" or blended course. These courses are blended, in the sense that the course has a fixed number of actual face-to-face classroom meetings, as well as a number of online sessions.

As well, students are choosing to create what would have to be called a blended set of courses for themselves. Undergraduates sign up for three or four face-to-face classes, and then register for one additional $100 \%$ online course. Graduate students often take one course face-to-face and one course online each semester. In both cases, quicker time to completion is made possible by this blended solution, as well as more personal and professional flexibility. For the 2005-2006 academic year, an additional $15 \%$ of the University's students took at least one $100 \%$ online (ALN) course. Students are clearly telling us that blended education works for them, quite effectively.

Blended learning also is providing the Seidenberg School and the University with new options for corporate clients as well. All current conversations with corporate clients include references to the fact that education can be provided three ways: $100 \%$ on-ground; $100 \%$ online; and blended. For both the University and for corporate clients, blended learning is increasingly becoming an attractive and important option. The corporations like working with a local University, one that is within easy commuting distance for their employees. In addition, corporations like to include employees who are at somewhat remote locations (30 to 40 miles away) as well. Blended learning makes this possible and appealing. Individuals who work at somewhat remote locations may wind up in blended classes, ones that offer a mixture of face-to-face and online instruction. They can still participate with the local University and the local initiative, but they can remain in their somewhat remote location.

It is clear that blended learning is here to stay. Blended learning, whether it occurs within a course or a certificate or a degree, offers both the University and students increased flexibility. All of this bodes well for the future.

\section{ABOUT THE AUTHOR}

David Sachs is Associate Dean and Professor of Technology Systems in Pace University's School of Computer Science and Information Systems. As Associate Dean, he has been actively involved in the development and implementation of computer science and telecommunications courses for the corporate community since 1984. As supervisor of the Pace Computer Learning Center, Dr. Sachs is responsible for the many hundreds of days of personal computer, computer science, and telecommunications education that are provided each year to corporations throughout the United States and around the world such as AT\&T, IBM, MCI, PepsiCo, The Reader's Digest, and others. Dr. Sachs has worked closely with teachers, administrators and others to think about the most effective ways to introduce technology into public and private schools.

Most recently, he has been actively involved in the development of courses to be taught asynchronously over the Internet and the World Wide Web. Dr. Sachs is Co-Director of the NACTEL Program (http://csis.pace.edu/nactel), a program that provides an AS in Telecommunications Degree and a BS in Telecommunications Degree to many hundreds of individuals from Verizon, Qwest, SBC and Citizens, 
many of whom are members of CWA and IBEW. In addition, Dr. Sachs has been the Principle Investigator for a FIPSE Learning Anytime Anywhere Partnership Grant (1999-2002) as well as for a grant from the Alfred P. Sloan Foundation (2002). 